\title{
Bricolaje institucional en la Amazonía peruana: la experiencia de una comunidad nativa 1
}

\section{Gisselle Vila}

Pontificia Universidad Católica del Perú

gvila@pucp.pe

RESUMEN

Este artículo explora el proceso de bricolaje institucional que se desarrolla en una comunidad nativa y que conduce a la creación de una comisión de regantes. A partir de una revisión histórica, se identifican las dinámicas de préstamo de arreglos previos, como relaciones familiares o modalidades de reunión, para dar sentido a nuevos marcos institucionales promovidos por proyectos de desarrollo, como el trabajo cooperativo o el pago de una tarifa por el uso del agua. El argumento sostiene que se trata de un proceso de alteración institucional, dado que no conduce a la creación de un nuevo organismo cualitativamente distinto sino que reproduce lógicas y acuerdos previamente establecidos.

Palabras clave: bricolaje institucional, Amazonía, pueblos indigenas, gestión integrada de recursos hídricos (GIRH).

Esta investigación se realizó gracias a la Beca Biocuencas, otorgada por Conservación Internacional y financiada por el Ministerio de Asuntos Exteriores de Finlandia. 


\section{Institutional bricolage in Peruvian Amazonia: a native community's experience}

\section{ABSTRACT}

This article explores the institutional bricolage process developed in a native community, which derives in the creation of a water user's association. Based on a historical review, the article identifies the borrowing dynamics from previous arrangements, such as family relationships and meetings, in order to make sense of the new institutional frameworks promoted by development projects, such as cooperative work and the payment of a water tariff. The argument proposes that this is a process of institutional alteration, because it does not led to the creation of a qualitatively different organism, but rather it reproduces previously stablished logics and agreements.

Keywords: institutional bricolage, Amazonia, indigenous people, integrated water management (IWM). 


\section{INTRODUCCIÓN}

Las dimensiones locales para el gobierno hídrico en la cuenca amazónica son críticas para la implementación de políticas hídricas, especialmente de aquellas enmarcadas en la GIRH (gestión integrada de los recursos hídricos). Mientras se evalúa la capacidad de los gobiernos subnacionales para determinar la adopción de responsabilidades descentralizadas (Siegmund-Schultze et al., 2015; Abers, 2007) e impulsar nuevas arquitecturas institucionales (De Souza et al., 2014; Braga et al, 2011), poco se ha discutido sobre cómo se incorporan las políticas e instituciones de la GIRH en el ámbito local, especialmente en el caso de pueblos indígenas, cuyo territorio titulado cubre el $27,5 \%$ de la cuenca (RAISG, 2012).

La inquietud es acuciante debido al creciente interés del Estado peruano por controlar aguas amazónicas y por regular las prácticas de uso y acceso indígena. Así, la Ley de los Recursos Hídricos (promulgada en 2009) plantea la creación de consejos de recursos hídricos que incluyan usos locales y tradicionales indígenas en articulación con los principios de la GIRH. Por otro lado, el megaproyecto GEF Amazonas (Proyecto Manejo Integrado y Sostenible de los Recursos Hídricos Transfronterizos de la Cuenca del Río Amazonas) se ejecuta en el marco del Tratado de Cooperación Amazónica (OTCA) con el objetivo de promover la GIRH, para lo cual se conducen diagnósticos de prácticas indígenas de usos del agua.

Si bien para el caso peruano se han realizado ricas descripciones sobre las normas que regulan el acceso a recursos hidrobiológicos por la población ribereña (Soria y Rodríguez, 2008; Pinedo et al., 2002) e indígena (Borios, 2005; Garay, 2004; Rivas, 2004; Bergman, 1990), y se ha rendido cuenta sobre estrategias indígenas de resistencia ante la contaminación del agua y pérdida de acceso (Grados y Pacheco, 2016; Gamboa, 2014; Villacrez, 2012; Ráez, 2010), es necesario prestar mayor atención a la incorporación de políticas hídricas nacionales en prácticas locales. 
En este artículo se entiende tal incorporación como un proceso de bricolaje institucional; esto es, de préstamo de arreglos institucionales previos para reorganizar y dar sentido a nuevas arquitecturas de gobierno diseñadas para el manejo de recursos naturales. Para entender este proceso, se examina la creación de una comisión de regantes en la comunidad nativa awajún de Bajo Naranjillo, diseñada siguiendo los principios de la GIRH. El argumento sostiene que el ingreso de ese diseño no condujo a la institucionalización de nuevas prácticas de gobierno hídrico; más bien, la comisión se reacomodó en función de la preservación de los arreglos locales de poder que se sostienen en relaciones de convivencia y control territorial.

\section{BRICOLAJE INSTITUCIONAL}

El institucionalismo crítico plantea que las instituciones no son un mero conjunto de reglas que organizan la acción, sino el amalgamiento de sentidos intersubjetivos que se ponen en práctica en la vida cotidiana (Cleaver, 2012; Mehta et al., 2002). Para el caso del manejo de los comunes, esto significa que la acción colectiva es contingente a relaciones sociales, arreglos organizativos, valoraciones y creencias que escapan la lógica de la elección racional, aunque también podrían incorporarla. De ese modo, las instituciones para el manejo de los comunes rara vez persiguen el objetivo exclusivo de gestionarlos con criterios de costo y beneficio: el manejo de aguas, bosques y tierras se encuentra estrechamente vinculado con estructuras sociales, relaciones de poder, sistemas organizativos y ontologías (Benouniche et al., 2014; Mehta, 2000).

Las instituciones se actualizan y transforman en procesos de bricolaje, entendidos como los procesos adaptativos en los cuales las personas recurren a un repertorio de materiales existentes para responder ante nuevas circunstancias (Douglas, 1987), como formas de organización, relaciones sociales, tradiciones $y$, en general, formas regulares de hacer las cosas (Cleaver, 2012, 2002). Estos arreglos, al provenir de dinámicas aceptadas de organizar la vida social, envisten de legitimidad a las formas que adoptan cuando se mezclan y adaptan a nuevas circunstancias. Así, por ejemplo, la reunión del consejo tradicional de ancianos de Nkayi, villa comunal en Zimbawe, se convierte en una asamblea comunal para asignar derechos de uso de agua (Cleaver, 2000); la asamblea general de comunidades campesinas de Ayacucho, Perú, se adapta para crear una junta de usuarios de distritos de riego (Verzijl y Domínguez, 2015), o la organización social awajún se acostumbra a nuevas burocracias hídricas promovidas por el Estado. 
Si bien esta dinámica de préstamo puede resultar en nuevas instituciones con atributos distintivos y nuevos fines (Sehring, 2009), también puede conducir a dinámicas de alteración, esto es, al acomodamiento de formas burocráticas externas a instituciones locales (De Koning y Benneker, 2013; De Koning, 2011), lo cual involucra un gradual proceso de filtración de significados, aceptación y legitimización, o, en términos de Green (2009), de «acostumbrarse a algo que al inicio parece extraño [...] un proceso de domesticación en el que los actores sociales se ven obligados y están deseosos de establecer una relación formal con el objeto extraño que ha aparecido» (Greene, 2009, p. 37). En ese sentido, el bricolaje reconoce la asimetría en las relaciones de poder de los procesos de traducción institucional y sigue la experiencia de los grupos que deben adaptarse a las nuevas formas burocráticas, como la experiencia de los awajún durante la creación de la comisión de regantes promovida por el Estado peruano y la cooperación internacional.

En lo que sigue se revisará la creación de una comisión de regantes como un proceso de bricolaje institucional que resulta en una dinámica de alteración. Se prestará atención a las formas de organización social que existían antes de la llegada de la comisión, las formas en las que se adapta y las configuraciones resultantes.

\section{METODOLOGÍA}

Este es un caso de bricolaje institucional en el manejo local del agua en la Amazonía ante la inserción de nuevas arquitecturas hídricas. El caso de la comunidad nativa de Bajo Naranjillo en el valle del Alto Mayo resaltó rápidamente por ser la única comisión de regantes en el país con representación indígena en toda la Amazonía, algo que podrá replicarse en los próximos años con la implementación de la Ley de los Recursos Hídricos².

Con inspiración en el rastreo de procesos, se realizaron descripciones detalladas de momentos específicos que se puedan trabajar como evidencia explicadora de transformaciones institucionales (Collier, 2011). Este proceso se realizó en dos etapas. En la primera se realizó una reconstrucción rápida de la historia de la comunidad para identificar los momentos clave. La reconstrucción se realizó

2 El título X de la Ley de los Recursos Hídricos establece la creación de comités de subcuenca en la Amazonía, los cuales tienen la facultad de administrar los usos del agua. El proceso de creación del Comité de Subcuenca del Alto Mayo es uno de los primeros. 
consultando el Archivo Histórico de Moyobamba, revisando artículos académicos y periodísticos, y realizando entrevistas.

En la segunda etapa se examinaron en detalle las condiciones que precedieron a cada momento clave, sus desarrollos y los procesos que abrieron. Esta etapa se realizó aplicando entrevistas en profundidad (34) a los actores locales y regionales vinculados con el gobierno hídrico en la comunidad. También se incluyeron observaciones, diagramas y documentos que se obtuvieron del trabajo de campo. Todo el proceso duró un año y medio. Los principales detalles de la historia comunal y los tres momentos clave se ilustran en la línea de tiempo.

\section{Figura 1. Línea de tiempo}

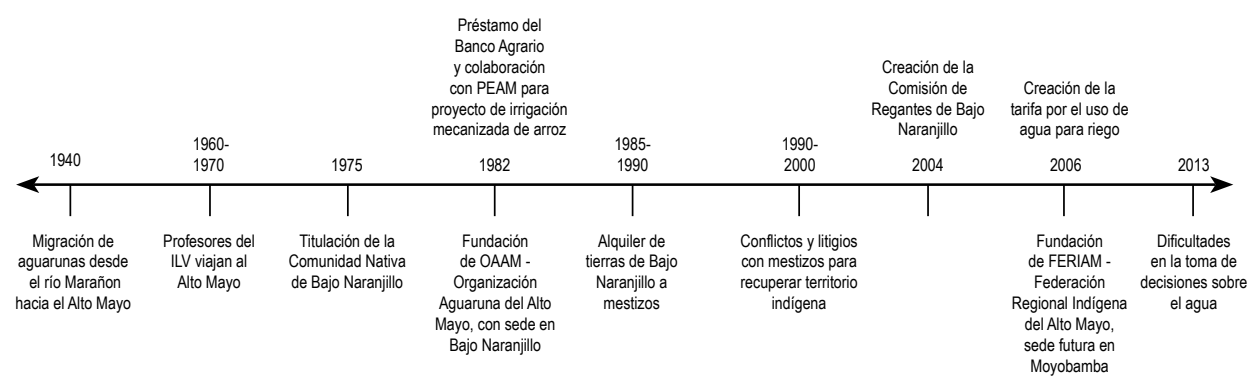

\section{BAJO NARANJILLO}

Bajo Naranjillo es una de las catorce comunidades nativas que se encuentran a lo largo del valle del Alto $\mathrm{Mayo}^{3}$, en la selva noroccidental del Perú. Administrativamente, el territorio se encuentra en el distrito de Awajún, provincia de Rioja, región San Martín. La principal vía de acceso es la Carretera Fernando Belaunde Terry. La comunidad se tituló el 22 de diciembre de 1975, con una extensión de 6642 hectáreas y ubicada en el margen derecho de la subcuenca Naranjillo, una de las trece tributarias del río Mayo. La comunidad tiene aproximadamente 1500 habitantes ${ }^{4}$ (IBC, 2016).

3 Denominación popular de la parte alta del río Mayo. Esta sección ocupa la mayor extensión de la cuenca y concentra también al mayor grupo poblacional (199 185 habitantes). En su margen derecho se encuentra el Bosque de Protección Alto Mayo, de donde emergen las principales subcuencas que alimentan al río (MINAM, 2009).

4 Bajo Naranjillo es la capital del distrito awajún. Cabe anotar que hay miembros de la comunidad que no residen en el territorio titulado, sino en la zona urbana del distrito, por lo que el total poblacional podría ser mayor. 


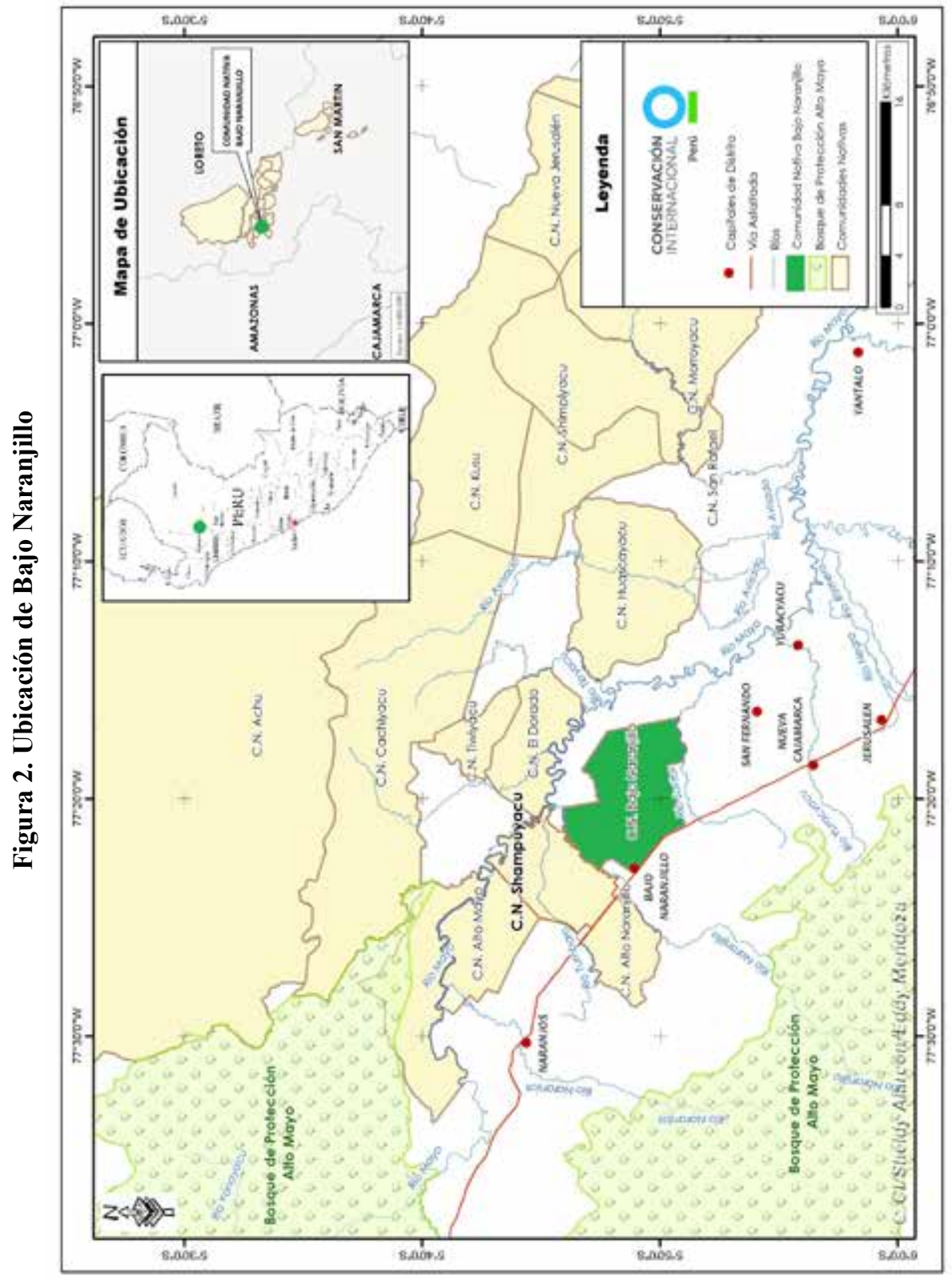

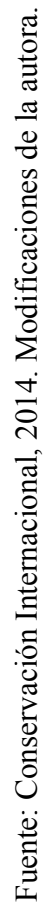


Los habitantes de Bajo Naranjillo son mayoritariamente awajún ${ }^{5}$, aunque existen también algunas familias wampis ${ }^{6}$. A pesar de compartir el $80 \%$ del vocabulario, y los mismos órdenes cosmológicos, se trata de dos grupos etnolingüísticos distintos ${ }^{7}$ que han sostenido disputas desde hace siglos (Regan, 2003; Guallart, 1990). La comunidad, sin embargo, sigue siendo mayoritariamente awajún. Esta distinción tiene implicancias en el manejo territorial e hídrico, como veremos más adelante.

Los awajún y wampis llegan al valle del Alto Mayo a lo largo de dos olas migratorias. La primera ocurre a inicios del siglo $\mathrm{XX}$, cuando un grupo de awajún procedentes del Alto Marañón se encontraba en búsqueda de zonas abundantes en animales y vegetación que no se encuentren bajo control de ningún patá ${ }^{8}$, aparentemente huyendo de conflictos con otros grupos (Brown, 1984). Esta migración, sin embargo, no sería tan significativa como la que vendría posteriormente desde la década de 1960. Habiendo concluido sus estudios como profesores bilingües gracias al apoyo del Instituto Lingüístico de Verano (ILV), un grupo de awajún viaja al valle buscando identificar a otros grupos de patá con el fin de organizarse. Con el tiempo, este grupo se instalaría, traería a sus familias, y sería el primero en definir las acciones awajún en el marco de la política indígena (Greene, 2009).

Bajo Naranjillo se convertiría también en un importante eje productivo en el valle del Alto Mayo. De destinar una o dos hectáreas para el cultivo de yuca y algunos frutos, en el marco de una economía familiar horticultora, los grupos familiares comienzan a trabajar de 10 a 15 hectáreas. El proceso se ve facilitado por el acceso a crédito agrícola. Paulatinamente esto condujo al ingreso de nuevos cultivos comerciales, como el café y el cacao en la década de 1990.

El agua es uno de los principales elementos articuladores de las culturas awajún y wampis. La ubicación al margen de una quebrada es estratégica en la medida en que facilita el acceso a recursos hidrobiológicos para subsistir, y permite una posición privilegiada para observar la llegada de enemigos y contar

5 Antes conocidos como «aguarunas». Awajún es el nombre que el grupo eligió para autodenominarse y proviene de «awap» (amigo). Aguaruna es el término colonial que se empleó tradicionalmente para referir al grupo awajún. En este artículo se empleará el término awajún.

6 Es el término que emplea el grupo para referirse a sí mismo. Antiguamente eran conocidos como huambisa.

7 INEI (2008) reconoce que existen 261 comunidades awajún y 61 wampis. Este dato censal no reconoce, sin embargo, la existencia de comunidades interétnicas. La comunidad nativa de Bajo Naranjillo, por ejemplo, quedó tipificada solo como awajún.

8 Generalmente comprendido como familia. La idea de familia en la etnografía jíbara es flexible y puede sobrepasar la idea de relaciones de parentesco cercanas (Uriarte, 2007). 
con una ruta de escape, de ser el caso (Greene, 2009). Así, los cursos de agua se cuentan entre los principales organizadores de grupos sociales. Los awajún y wampis emplean el nombre de las quebradas y cursos de agua para referir a los patá instalados en su margen (Greene, 2009). Es común oír tumbaru aents (la gente del río Tumbaro) o tioyacu aents (la gente del río Tioyacu). Con el tiempo, estos cursos de agua pasaron a nombrar a algunas de las nuevas comunidades, como es el caso de Shampuyacu o el de Bajo Naranjillo.

La comunidad irriga sus tierras canalizando las aguas de la subcuenca Naranjillo. El canal principal y los cuatro canales laterales registrados por la Comisión de Regantes de Bajo Naranjillo irrigan 2181 hectáreas: el 33\% del territorio comunal. El cultivo más importante es el arroz, aunque en los últimos años el cultivo de café y cacao se ha incrementado. Los titulares de cada predio en la comunidad arriendan sus tierras a empresas que procesan y venden arroz, lo cual generó conflictos sobre la propiedad de la tierra entre las décadas de 1980 y de 1990 (Urteaga, 1993). Actualmente, el principal arrendatario de las tierras comunales es la empresa Induamérica, una de las dieciséis agroindustriales de la provincia de Rioja dedicadas al procesamiento de arroz ${ }^{9}$.

Por su parte, los wampis se instalan en la comunidad recién a principios de la década de 1990, aunque algunas familias wampis sostienen que familiares suyos de generaciones anteriores ya conocían la zona de Bajo Naranjillo ${ }^{10}$. Dado que no formaron parte del grupo de beneficiarios que recibió crédito agrícola para el cultivo de arroz, los wampis se dedicaron primero a trabajar como peones en chacras awajún y $\operatorname{apach}^{11}$. Posteriormente se articularían mejor que los awajún al cultivo de café y cacao, gracias a la intervención de la cooperación internacional que en ese momento destinaba esfuerzos a la erradicación del cultivo de hoja de coca. Paulatinamente, algunos wampis se casarían con awajún y así tendrían acceso a las tierras comunales.

9 Desde 2009 San Martín es la principal región productora de arroz en el Perú. El 61\% de la producción de la región, para 2011, se concentró en el valle del Alto Mayo, generando US\$100 millones en ventas. Fuente: http://www.andina.com.pe/agencia/noticia-produccion-arroz-sanmartin-genera-mas-100-millones-al-ano-ventas-493900.aspx

10 Al ser un grupo minoritario en la comunidad, es posible que el relato se emplee para fortalecer su posicionamiento en proceso de toma de decisiones normalmente dirigidos por awajún.

11 Apach es un término que se emplea para referir, en general, a aquello que no forma parte de la cultura awajún. Cotidianamente es entendido como «mestizo» (Greene, 2009). Más adelante discutiremos el término. 


\section{UNA GRAN FAMILIA: LA CREACIÓN DE LA COMUNIDAD}

El proceso de bricolaje se rastrea desde los orígenes de la comunidad. En este período temprano las relaciones familiares, las dinámicas de reunión y el trabajo de la tierra fueron readaptados para responder ante las crecientes presiones sobre el territorio, tanto por los invasores como por el Estado. Exploraremos este proceso en dos eventos estrechamente relacionados: la creación de la comunidad y el acceso a crédito agrícola.

Los awajún que vivían en Bajo Naranjillo habían estado ya en contacto con migrantes andinos desde antes de la creación de la comunidad. Los awajún trabajaban para ellos estacionalmente en los períodos de estiaje, cuando el río bajaba de caudal y el acceso a alimentos era limitado. Sin embargo, a fines de la década de 1960, numerosos grupos de migrantes llegaron vía la aún incompleta Carretera Marginal de la Selva, buscando terrenos fértiles de cultivo. Ellos invadieron el territorio ocupado por los awajún.

Durante el mismo período, un grupo de profesores del ILV llegó al valle desde la provincia de Condorcanqui, en la región Amazonas. Adolfo Juép e Israel Katíp ingresaron por el nororiente, dirigiéndose hacia la zona intermedia. Se instalaron en las orillas del Bajo Naranjillo por su ubicación estratégica en el valle, colindante a lo que sería la carretera Marginal de la Selva, en el punto medio entre Moyobamba (capital de San Martín) y la entrada a la región Amazonas, y con un bosque con una pendiente amigable en comparación con los montes escarpados que se pueden encontrar en otras zonas del valle. En Bajo Naranjillo ya se encontraban algunos grupos poblacionales. Son recordados los pijush, putjuk y yagkitai. En ese entonces eran reconocidos como naranjillo aents (gente del río Naranjillo).

Los profesores del ILV, quienes venían informados de los primeros avances de la reforma agraria y contaban con vínculos con la oficina de SINAMOS ${ }^{12}$, propusieron la organización en comunidades para hacer frente a la invasión apach. Pero, como Noé Cahuaza recuerda, «no todos entendían qué significaba pertenecer a una comunidad, todos habían vivido como familia, grupo, de cerca o de lejos, pero juntarlos todos no tenían idea». La idea de «familia» —o patá, como refiere Noé- había sido la figura más cercana de organización en las vidas de quienes vivían en las orillas del Naranjillo. Cuando refiere «de cerca o de lejos», se refiere tanto a la distancia geográfica entre patá como a la proximidad del

12 Sistema Nacional de Apoyo a la Movilización Social. Organismo del Estado dedicado a apoyar esfuerzos asociativos de la sociedad civil, desactivado en 1978. 
parentesco, pues, como propone Greene (2009, p. 74), «la relación entre genealogía y geografía es literal». De ese modo, lo que se entiende como un familiar lejano alude tanto a la distancia genealógica como a la distancia en el camino ${ }^{13}$.

Un elemento importante en la constitución de la comunidad fue crear vínculos familiares. Al principio, los profesores se instalaron cerca de la desembocadura del Naranjillo, lejos de los grupos familiares aguas arriba. Pero la distancia se fue reduciendo a medida que los profesores traían a sus parientes para instalarse en el valle. Esto condujo a la aparición de las primeras uniones entre los recién llegados y los antiguos residentes. El «acercamiento» ocurrió también a partir del rastreo de ancestros en común, aunque, como recuerda Irma Wajajai, «no había cómo comprobar que eran parientes de verdad; decían que el abuelo venía de la misma zona y hablaban de algunos nombres iguales [...] pero en la tarde, después de pescar, decían "¡este es mi hermano!"» Como revela el pasaje, la proximidad entre parientes no se sostenía solo en lazos de sangre, sino también en vínculos colaborativos ${ }^{14}$. Compartir la pesca, la caza y hacer frente a una amenaza común sirvió para acercar a los grupos familiares. Con el tiempo, los profesores se mueven de la desembocadura del Naranjillo y se acercan a otros grupos familiares.

Los vínculos entre familias fueron el soporte que permitió fundar la comunidad nativa de Bajo Naranjillo en 1975, al amparo de la legislación peruana. En palabras de Adolfo Juep, «el decreto ley 20653 decía "comunidad nativa es todo grupo de familias unidas por cultura, idioma, asentamiento, vínculo social, que han nacido ahí"; veníamos de afuera la mayoría, en común todo, tal vez no todos la misma habla, pero todos teníamos familias unidas, todos como un apui pata». Las diferencias de habla a las que refiere Juep, y algunas diferencias culturales, se refieren a la existencia de algunos wampis de mestizos en la zona.

Sin embargo, tales diferencias fueron superadas considerando al grupo de residentes en Bajo Naranjillo como un apui pata, una familia grande. Si bien no eximido de otros atributos, el eje sobre el que se traslada la idea de «comunidad» de la ley es la idea de familia y, específicamente, de las relaciones entre grupos familiares. Pero a pesar de ser el elemento que unifica, la idea de familia es también aquella que divide: a pesar de convertirse en una comunidad nativa ante la ley, las lógicas de acción colectiva para el manejo de agua y tierras no aterrizan. La legitimidad

13 No es el objetivo de este artículo ofrecer un recuento detallado de las relaciones de parentesco en la sociedad awajún. Para ello se pueden ver los trabajos de Larson (1977), Taylor (1998), Regan y Paz (2008) y Tello (2001), entre otros.

14 Es posible que las lógicas andinas de apoyo y reciprocidad también se hayan filtrado en este proceso a partir de uniones matrimoniales entre awajún y migrantes. 
que la idea de familia porta para articular una comunidad tiene limitaciones. Por eso la comunidad divide el territorio entre quienes se reconocen como jefes de familia. Y por eso sucede un conjunto de consecuencias producto de las decisiones contingentes de diversos subgrupos familiares, como veremos a continuación.

\section{LOS AWAJÚN Y EL DESARROLLO AGRÍCOLA}

La titulación no impidió que los migrantes andinos invadieran la tierra de los awajún. Los enfrentamientos continuarían en el tiempo, hasta llegar incluso a amenazas de muerte. El diario El Comercio, en su edición del 2 de junio de 1976, titula «Denuncian a colonos que ponen trampas mortales donde viven aguarunas. Dicen que tomarán "medidas especiales" ante falta de atención por parte de autoridades». Para frenar el avance de los invasores, algunas familias comienzan a cultivar arroz seco en sus predios familiares (Works, 1987), incentivados por las ideas de los primeros extensionistas agrarios que visitaban el valle y encontraban a las tierras «ociosas». Sin embargo, al ser una sociedad horticultora donde el trabajo de la tierra era cumplido por mujeres, el desarrollo del trabajo agrícola fue muy complicado en Bajo Naranjillo y se convertiría, décadas después, en una de las principales fuentes de conflicto.

No todas las familias estuvieron de acuerdo, dado que todas las labores vinculadas con el cultivo de la tierra eran cumplidas por mujeres. La mujer awajún, tradicionalmente, ha sido responsable de la horticultura. El conocimiento transmitido de madre a hija sobre las formas de cultivar distintas variedades de tubérculos y otras plantas se encuentra estrechamente vinculado con el respeto y observancia de las relaciones entre yumi, «agua» ${ }^{15}$ y nugkui, «subsuelo» (Regan, 2003). El trabajo horticultor tenía que ser riguroso, pues no solo involucraba la comprensión de elementos físicos para labrar la tierra, sino también el entendimiento de su vinculación con la ontología awajún. "Antes cultivar yuca era un arte. Salían distintos tipos. En la chacrita la mujer hacía su invocación y colocaba la semilla de una manera para que salga dulce, de otra manera para que salga salada [...]. Ella solita, a veces con mi hermana, construía sus ramalitos, para que en el calor no se seque la yuca» (entrevista 6, 17/01/14).

15 Según Calderón (2013), yumi significa «lluvia» para los awajún y wampis de la región Amazonas y tsugki es la denominación de la deidad vinculada con el agua. Sin embargo, prefiero emplear el término yumi, dado que es el que se emplea en Bajo Naranjillo para aludir al agua en general. 
Para cultivar arroz en cantidades suficientes se necesitaba del involucramiento de los hombres, y no todos estaban dispuestos a colaborar, dado que el trabajo de la tierra era femenino. Algunos decían que la tierra se podía enfermar si los hombres comenzaban a trabajarla. Otros, que era mejor conducir una acción de guerra para frenar a los apach. Mientras tanto, las familias que optaron por cultivar arroz se reunieron en una cooperativa, gracias al apoyo del SINAMOS, y asistieron a talleres de planificación agraria y mejoramiento de cultivos. Gracias a ello, el cultivo de arroz se incrementó a fines de la década de 1970, pues todos los integrantes de la cooperativa colaboraban con el trabajo de los predios. Como recuerda la hija de uno de los primeros residentes de Bajo Naranjillo, «mina apag ipamawai ajan takastatus» («mi padre invitó a varias personas a limpiar la chacra»). Estas primeras acciones colaborativas agrícolas cimentarían la resignificación del ipamat, la acción de invitar, que se comprendería más adelante como «invitar para ayudar» (Noé Cahuaza, 29/03/14). En el seno de estas reuniones emerge la necesidad de contar con más apoyo: recursos para seguir trabajando la tierra.

En coordinación con otros grupos de awajún del valle, a fines de la década de 1970 se funda en Bajo Naranjillo la primera organización indígena que reuniría a los pueblos del Alto Mayo: la OAAM ${ }^{16}$ (Organización Aguaruna del Alto Mayo). La OAAM es resultado de un gran ipaатати o reunión entre distintos grupos. Si bien el ipaаmamu no necesariamente conduce a trabajos colectivos, en este caso concluyó en la creación de una nueva instancia representativa que pudiese ayudar a los awajún a mejorar su trabajo en la tierra y detener a los invasores. Como dijera Adolfo Juep: "Ahí la reunión fue para ayudarnos a nosotros». En este momento el ipaamamu se redefine como la dinámica de colaboración entre familias para alcanzar un fin común. Deja así de ser solo una reunión para discutir y se convierte en un mecanismo de apoyo mutuo. De ese modo, una práctica común de convocar a una reunión se resignifica ante nuevos retos cooperativos y queda impregnada de nuevos usos ${ }^{17}$. Años más tarde, la limpieza de los canales de riego de la comunidad se organizaría a través del iраaтати, «una costumbre muy antigua de los awajún», según uno de los niños de la escuela bilingüe instalada en la comunidad, quien ignoraba los orígenes más bien recientes de la práctica. El ipaататu es hoy en día el principal mecanismo colaborativo en Bajo Naranjillo.

16 Desde 2004 llamada FERIAM (Federación Regional Indígena del Alto Mayo). El cambio de nombre se debe a que busca representar también a otros grupos etnolingüísticos, como los wampis y los lamas, entre otros.

17 Otra reinterpretación del ipaamamu es la de mecanismo de consulta (Greene, 2009; Sarasara, 1999). 
Bajo Naranjillo se constituiría como uno de los principales nodos del movimiento indígena amazónico en el norte del país, tanto por su importancia política como por su importancia económica (Brown, 2012). La OAAM cumple un rol fundamental como interlocutora entre los extensionistas agrarios que recorrían el valle y los awajún, y es la principal instancia responsable de la canalización de fondos para el desarrollo agrícola otorgados por el Proyecto Especial Alto Mayo (PEAM) y el Banco Agrario. En 1981, la Presidencia del Consejo de Ministros de Perú creó el PEAM, una de las principales iniciativas de desarrollo agrícola en la Amazonía peruana, cuyo objetivo fue incrementar la productividad agropecuaria y elevar los niveles de ingresos de 12800 familias (Ocampo, 1994, p. 156). Para ello, el PEAM se alía con el Banco Agrario y entregan 3800 créditos agrarios.

Gracias a la promoción de ambas agencias, a partir de 1982 la producción de arroz se incrementa drásticamente. El número de hectáreas de arroz prácticamente se cuadruplica en este año, en comparación con el anterior. El incremento en el cultivo de arroz en Bajo Naranjillo contrasta además con el crecimiento de otras comunidades en el valle, como Alto Naranjillo y Shampuyacu, quienes también reciben créditos para el cultivo, pero en menores cantidades. Según Cristóbal Juep, «la OAAM en Bajo Naranjillo ayudaba, que esté acá, si no en Moyo [Moyobamba, capital de la región San Martín] para qué nos iba a ayudar, en ir y venir se iba el tiempo y la inversión». Así pues, la instalación de la OAAM en la comunidad ayudó a que canalice mejor que otras comunidades los fondos para el desarrollo agrícola.

En 1982, Bajo Naranjillo recibe un préstamo de 128 millones de soles que tendrían que utilizarse para la adquisición de un tractor y la mecanización del cultivo irrigado de arroz que involucraba la construcción de canales de riego (Works, 1984). El proyecto contemplaba contar con 300 hectáreas cultivadas para 1988 e involucraba la participación activa y constante de todos los miembros de la cooperativa quienes, con el apoyo del tractor, podrían desbrozar la tierra y cultivar un promedio de 50 hectáreas al año que se incrementaría hasta alcanzar la meta.

El ipaanamu fue puesto a prueba. Al principio, casi todos los miembros de la cooperativa colaboraron con las actividades de remoción de tierra y retiro de maleza para preparar las chacras y construir el canal. Sin embargo, dado que el cultivo de arroz no brindaba rendimientos inmediatos, el trabajo no era constante, pues los awajún debían destinar otras partes del día a otras actividades, como la cacería y la pesca. Para algunos, incluso, el cultivo del arroz carecía de un fin comercial y se realizaba solo para demarcar el alcance del territorio indígena y 
así prevenir más invasiones. El ipaanamu no pudo solucionar el problema. No fue pensado para responder la demanda laboral del monocultivo de gran escala. Tampoco logró que todas las familias participaran por igual. Los arreglos de acción colectiva se comienzan a desdibujar.

El proyecto se desaceleró más aún con la demora en la entrega del tractor. Incluso cuando este llegó, cuatro meses tarde y con el período de siembra ya avanzado, luego se descompuso y tuvo que ser trasladado hasta Lima para ser reparado. La siembra se demoró dramáticamente, y al llegar 1983 no se pudo cumplir con las metas establecidas (Works, 1984). Peor aún, los awajún tenían la responsabilidad de pagar por el crédito al que habían accedido. Las notificaciones del Banco Agrario no se hicieron esperar y tuvieron que pensar en soluciones inmediatas. Dado que el único bien con que contaban era la tierra, los awajún decidieron ponerla en alquiler. Esta fue una medida desesperada que arrastraría un conjunto de perjuicios en las siguientes décadas, entre ellos, el despojo de tierras y, más adelante, la enajenación de los derechos de uso del agua.

Este período define nuevas relaciones respecto del uso y acceso al agua y su relación con la tierra. El arte de cultivar, ese matrimonio entre agua y tierra, cuidadosamente observado por las mujeres awajún, deja de ser una práctica necesaria para la subsistencia y quiebra, incluso, las relaciones de producción sostenidas en el género. La mujer deja de proveer a la subsistencia de los miembros de la familia cuando pierde sus chacras y se monetariza la economía local. Los hombres se convierten en los titulares responsables de los predios agrícolas. Como consecuencia, el trabajo masculino se intensifica y el trabajo femenino pierde protagonismo, lo que, a su vez, conduce a una menor participación en las decisiones sobre agua y tierras.

La comunidad nativa, primero, y la cooperativa, después, fueron arquitecturas gubernamentales promovidas por distintos órganos de gobierno con el fin de ordenar y controlar el uso y acceso a recursos naturales, e incluso su comercialización. Ambas categorías, sin embargo, son reajustadas a los fines locales de defensa territorial a partir de la resignificación de las ideas de familia y reunión.

En esta época se construyen también los primeros canales de riego, diseñados de modo tal que irriguen las tierras de las familias vinculadas con la cooperativa. Esta distribución del agua dejará una huella importante en los años venideros y será uno de los temas de discusión durante la creación de la comisión de regantes. 


\section{LA CREACIÓN DE LA COMISIÓN DE REGANTES}

La década de 1990 planteó varios cambios a los awajún y wampis de Bajo Naranjillo. En primer lugar, los awajún disputaron en instancias legales, formales e informales la tenencia de sus tierras, ganando en algunas y perdiendo en otras. Todo el proceso involucró la inversión de fuertes sumas de dinero en abogados y asesoría legal, con lo que el ahorro comunal se redujo. Algunos awajún se acercaron más a otras instancias del Estado gracias a este proceso, con experiencias variadas, ganando aliados en algunos casos. En vinculación con ello, nuevos proyectos de desarrollo llegan a la comunidad. Tan solo entre los años 1995 y 2000 se registraron veintiún proyectos en territorio comunal, todos conducidos por organismos del Estado (el gobierno regional, gobiernos locales, ministerios), ONG y organizaciones de cooperación internacional. El desorden en la implementación de esos proyectos fue tal que una chacra de la comunidad podía tener hasta tres usos distintos según el proyecto en cuestión.

La década de 1990 se encuentra marcada también por la explosión del cultivo de hoja de coca en San Martín. En respuesta se promueve el desarrollo de cultivos alternativos, como el café y el cacao. El fenómeno coincide con la llegada de un grupo de wampis a la comunidad. Dado que buena parte del territorio comunal cultivado con arroz se encontraba en litigio, los wampis se instalan en tierras no ocupadas y se articulan rápidamente a los proyectos de desarrollo alternativo promovidos por la cooperación para el desarrollo en concertación con el gobierno regional. Así ingresan a la comunidad cultivos de café y cacao. Las tierras de wampis, sin embargo, ocupan los últimos turnos de irrigación de los canales.

Los predios awajún se encuentran alrededor del canal Bajo Naranjillo y sus respectivos canales laterales (ver figura 3). Las cinco familias más antiguas en la comunidad concentran el $70 \%$ del territorio irrigado, el cual representa también el 38\% de todo el territorio de la comunidad. Esto se debe a las relaciones interfamiliares y la disposición de parientes cercanos en el territorio. Tal situación no impidió que existieran matrimonios entre awajún y población migrante, ni que hoy en día esos migrantes trabajen en el territorio de la comunidad. No obstante, los esfuerzos por tratar de controlar los matrimonios entre awajún e incluso wampis existen y encontrarán una ventana de oportunidad ideal, como veremos en breve.

Tres de las cinco familias más antiguas son awajún. Las dos familias restantes son wampis y son las únicas de este pueblo indígena que se dedican al arrendamiento de tierras para el cultivo de arroz, pues forman parte del grupo de familias más antiguas de la comunidad, instaladas antes de su creación. Las nuevas familias 
Figura 3. Canales en la comunidad nativa de Bajo Naranjillo y familias

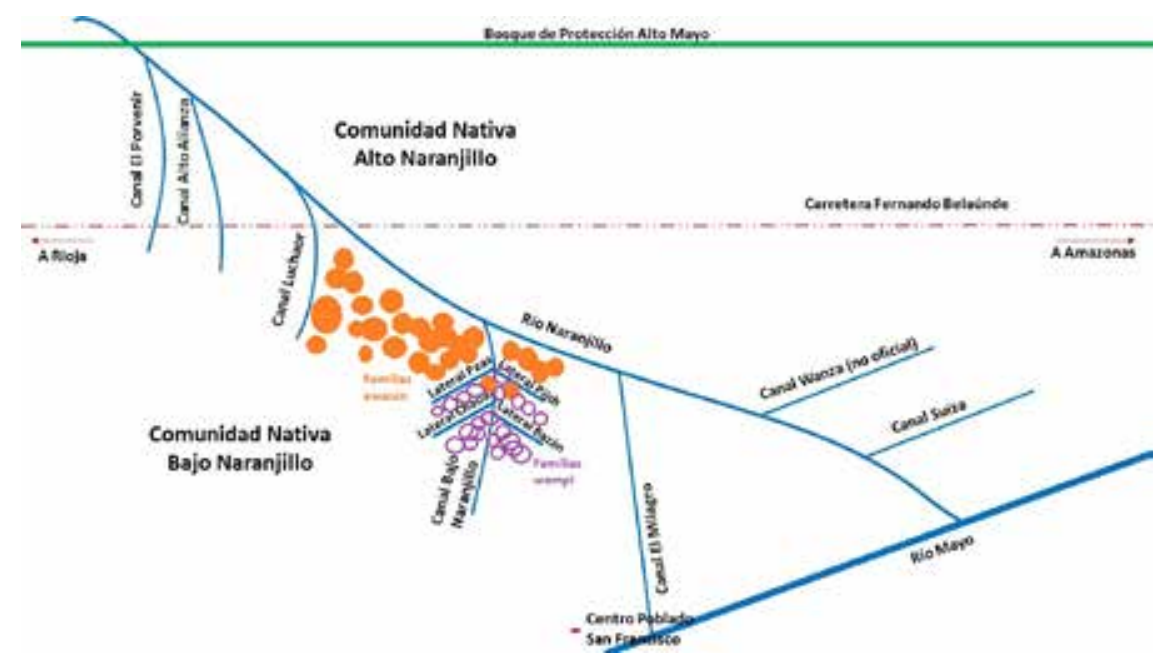

Fuente: Trabajo de campo y observaciones de awajún y wampi. Elaboración propia.

wampis que llegan en la década de 1990, se ubican aguas abajo de los canales de riego. Sus decisiones agrícolas dependen en buena medida de las decisiones que tomen los awajún aguas arriba.

En el año 2003 el Estado peruano buscaba maneras de mejorar la transparencia, participación en el gobierno y uso eficiente de recursos, luego de uno de los períodos más corruptos en la historia republicana. En ese espíritu, el Estado central convoca la creación de una comisión técnica multisectorial que tuvo por objetivo el diseño de un plan concertado para el sector agua (Oré y Rap, 2011). La necesidad de promover un enfoque integral se planteó y rápidamente se impuso como el norte de las nuevas políticas hídricas.

La cooperación internacional cumplió un rol fundamental en promover las bases del enfoque integral para la promoción del agua, que posteriormente sería simplemente entendida como GIRH. En el mismo año, el gobierno regional de San Martín firmó un convenio con GTZ (Cooperación Alemana para el Desarrollo) para promover la gestión integral del agua en la región a través de la creación de comisiones de regantes. Para ello, se alió con la Administración Técnica del Distrito de Riego de Rioja, organismo dependiente de la Autoridad Nacional del Agua del Ministerio de Agricultura. La visita a Bajo Naranjillo fue una de las primeras pues, como dijo uno de los consultores responsables del proceso: «El caso de Bajo Naranjillo destacaba sobre otros debido a que no solo irrigaban cientos 
de hectáreas de arroz, sino que habían logrado contar con infraestructura para la construcción de canales de riego, a diferencia de otras comunidades nativas donde a duras penas han juntado ahorros para comenzar a revestir [los canales]». La discusión que emerge en la comunidad para crear la comisión de regantes puede comprenderse en dos dimensiones: valoraciones y autoridad.

La comisión buscó enmarcarse como un organismo que suscribe los principios de la GIRH, especialmente el principio de uso eficiente del agua. La eficiencia fue explicada como el pago justo por la provisión de agua para riego, lo cual implicaba crear una tarifa por el uso del agua. Normalmente, cualquier comisión de regantes define la tarifa a pagar como resultado de un proceso interno de medición de caudales, usos promedios según cultivos y temporadas, número de miembros, demanda hídrica, entre otras variables. Las juntas de usuarios, instancia superior a las comisiones de regantes, suelen proveer asistencia contratando profesionales (ingenieros agrícolas y economistas) para asistir el proceso. Las juntas tienen, además, la obligación por ley de recaudar los ingresos por el pago de la tarifa y entregar un porcentaje al Estado, por concepto de mantenimiento de infraestructura y uso del recurso. En caso de no cumplir, la comisión de regantes corre el riesgo de perder el acceso al agua y podría recuperarlo solamente pagando una multa.

Toda esta información generó confusión en Bajo Naranjillo debido a que, desde su perspectiva, el Estado no había invertido en la comunidad. La infraestructura agrícola con la que contaban era resultado de un préstamo cancelado en su totalidad.

[Los canales de] Bajo Naranjillo, El Milagro, acaso los del ATDR querían cubrir. Nosotros hemos tenido que ir y llevar nuestro perfil de proyecto a Rioja, al PEAM, a Moyo, para que lo saque. Y esos nos querían cobrar. Yo me reía. Ya qué podía hacer. Años preocupados porque el apach invada nuestra tierra [...], pero viene el apach más grande y tranquilito nomás nos dice «paga» (entrevista 7, 17/01/14).

No puede interpretarse directamente que el Estado peruano es comprendido como «mestizo»o «colono» en esta frase. Apach, de hecho es un término bastante más complejo que se puede referir, básicamente, a quien no es awajún o a aquello que no puede caracterizarse como awajún. En ese sentido, lo apach puede referir a un conjunto de atributos que incluso un awajún puede presentar cuando tiene una conducta o una presentación que se acerca a la usanza occidental. En la cita, lo «apach» caracteriza tanto a un tipo de sujeto como a un tipo de conducta, e incorpora una reflexión sobre cómo han cambiado en el tiempo. Mientras que 
el apach de las décadas de 1980 y 1990 usurpaba tierras usando la fuerza, en 2000 el apach deja la violencia por la ley que brinda el sustento (la tranquilidad) suficiente para demandar una contraprestación. Este segundo tipo de apach tiene más mecanismos de control y más herramientas —y por eso es más grande — para lograr lo que busca. Si antes se podía responder en los mismos términos, repeliendo a los invasores con la guerra, el apach contemporáneo los inmoviliza («ya qué podía hacer») y obliga a pensar más allá de las acciones bélicas. De este modo, la idea de apach se emplea para caracterizar a un Estado peruano no awajún.

Los nuevos liderazgos awajún tienen la responsabilidad de responder ante tales retos. Si bien las acciones tradicionales de guerra son menos frecuentes, las jerarquías de gobierno en las sociedades awajún y wampis siguen remitiéndose a los roles que cumplían las personas en tiempos bélicos (Romio, 2014). Así, una de las posiciones de liderazgo es designada bajo el rol del Pamuk, la figura del anciano guerrero que ha dispuesto acciones bélicas, usualmente uniendo a distintos grupos familiares en torno a un objetivo común (Greene, 2009). Se trata de alguien con experiencia en la guerra y con la capacidad de brindar consejo y guía sobre nuevos conflictos. En Bajo Naranjillo, el presidente de la comunidad es llamado Pamuk, haciendo eco a la necesidad de liderazgo en acciones de defensa. Sin embargo, en la actualidad, el cargo no es suficiente para investir de autoridad las decisiones tomadas, como se verá ahora. En las sociedades awajún y wampis se espera que el individuo se realice y sea merecedor de la denominación (Brown, 2014).

La Junta Directiva de Bajo Naranjillo era la interlocutora oficial de la comunidad ante el Estado y la cooperación internacional. Al llegar la propuesta de crear la comisión de regantes, el Pamuk de la comunidad convoca a una reunión para discutirla. Esta, sin embargo, carece de quorum y no se puede realizar. Debido a ello, el Pamuk declara que no se respaldará la creación de este nuevo organismo y publica la resolución en la puerta del local comunal. Estas resoluciones, usualmente, emergen como parte de un proceso deliberativo donde se cuenta con el liderazgo de un pamuk que organice las acciones. Por eso la conducta del presidente fue criticada por los awajún. Según una de las habitantes de Bajo Naranjillo que estuvo atenta al proceso, «cómo habrá creído que pegar su firma en la puerta es todo lo que necesitamos». En la misma línea, otro informante comenta «detrás de tanto papel, ¿qué hay? ¿Una mirada? ¿Una inspiración?... Vacío está».

Ambas declaraciones aluden a la burocratización de los procesos de toma de decisión al interior de la comunidad, y cómo estos aún despiertan suspicacias entre los awajún y los wampis, en modo análogo a lo que ocurre con la actitud apach 
del Estado. Detrás de las firmas y los papeles no se encontraría la determinación necesaria que cualquier líder necesita para realizar una empresa, pues para los awajún y los wampis, solo los guerreros que acceden a la revelación del ajútap ${ }^{18}$ y la ponen en práctica podrán conducir vidas plenas (Romio, 2014). ¿Quiénes tienen la capacidad de enfrentar las nuevas prácticas formalizadoras del Estado y responder en sus términos sin traicionar los principios awajún y wampis? ¿Dónde encontrar a los verdaderos pamuk? Estas preguntas, además, se plantean durante el proceso de transformación de OAAM en FERIAAM (Federación Regional Indígena del Alto Mayo), en un intento por incorporar la diversidad interétnica del valle. Para ello, la sede se traslada a la capital de la región, Moyobamba. Bajo Naranjillo perdía así un importantísimo órgano político.

La discusión sigue la ruta de los canales y en las bocatomas: a la hora de cambiar los turnos de agua, se desarrollan reuniones improvisadas. Los rumores de que la presidencia de la comunidad los ha traicionado siguen creciendo, y mientras tanto, el comité impulsor de la GIRH espera respuestas sobre la creación del nuevo organismo. Un grupo de awajún liderado por Noé Cahuaza, conocido líder que ha ocupado una miríada de cargos en la organización indígena, asume el liderazgo en la discusión. Noé, además, es un viejo conocido de procedimientos del Estado, respetado por los Cahuaza y por otras familias. Inmediatamente su liderazgo es respaldado por otros grupos familiares, especialmente por los más antiguos de la comunidad. De ese modo, los grupos familiares awajún se alinean detrás de una figura de liderazgo indígena y se alejan de una figura de autoridad planteada por las lógicas del Estado: el presidente. El verdadero pamuk ha sido encontrado.

Uno de los principales puntos críticos en la discusión fue la incorporación de población migrante en la comisión. Como la subcuenca Naranjillo atraviesa más centros poblados, además de la comunidad, era necesario incluirlos en los procesos de discusión, e incluso darles la posibilidad de colocar a sus representantes en la comisión. Considerando la historia entre los awajún y los migrantes andinos - algunos de los cuales seguían viviendo en tierras indígenas que habían invadido-, las posibilidades de llegar a un acuerdo eran remotas.

18 El ajutap o arutam es la entidad que debe ser poseída por el hombre jíbaro para conducir una vida plena, caracterizada por la confianza, seguridad, honestidad y otros atributos vinculados con el carácter. Si bien su naturaleza es incierta, sus efectos son reconocidos como un punto de quiebre en el ciclo de vida de la persona. En términos de Taylor (1993, p. 666): «El arutam sirve como un amplificador existencial; no solo da vida sino, más importante aún, da vida con dirección o cualidades, una vida vinculada con un conjunto de valores» (traducción propia). 
Un día, por error, alguien se olvidó de abrir la compuerta para que el agua llegase a todos los predios aguas abajo y hubo quejas, porque se había perdido un día de riego. Inspirado, el grupo liderado por el verdadero Pamuk tuvo una idea. Plantearon un nuevo acuerdo sobre cómo relacionarse con los apach: si ellos se retiraban de las tierras invadidas, tendrían acceso al agua con regularidad. Si no lo hacían, esta se cortaría. Las capacidades para aplicar la penalidad existían, dado que las familias antiguas se instalan en las proximidades del canal principal, del que derivan todos los otros canales. Es más: incluyeron como parte del acuerdo para acceder al agua la limitación de los matrimonios entre awajún y migrantes andinos, discutiendo ocasiones permisibles y constricciones a la heredad de tierra.

Los colonos de los asentamientos vecinos estuvieron de acuerdo con los nuevos términos. Tenían muy poco espacio para negociar. Era un grupo que dependía totalmente de la agricultura y que trabajaba la tierra con sus propias manos. La falta de acceso al agua pondría en riesgo su bienestar. Las familias awajún más antiguas, entonces, decidieron respaldar la creación de la comisión de regantes. La GTZ y el gobierno regional habían propuesto que se tratase de un «organismo indígena», colocándola como una subdirección del comité directivo de la comunidad nativa, pero luego del incidente con la presidencia, y habiendo llegado a nuevos acuerdos con los colonos, se optó por que la nueva comisión fuese un organismo independiente de la comunidad nativa. Solo de esta manera se podría controlar la participación de los colonos: haciéndolos usuarios de agua para riego.

La Comisión de Regantes de Bajo Naranjillo se creó en el año 2004. En las primeras elecciones salió elegido un presidente awajún proveniente de una de las familias antiguas. Como parte del apoyo de GTZ, se crearon estatutos y libros registrales, entre otros documentos, todos guardados por si eventualmente eran solicitados por alguna instancia del gobierno o como sustento de algún trámite para gestionar nuevos proyectos.

Posteriormente, en 2006, se creó la tarifa por el uso agrícola del agua muy a pesar de la resistencia de los awajún, quienes sí estuvieron a favor de la creación de la comisión. Los argumentos para evitarlo fueron varios. Por un lado, hubo quienes sostuvieron que yumi no podía ser controlada por el dinero o la infraestructura, desvirtuando la figura del pago por un servicio constante. Hubo también otras intervenciones que sostuvieron que pagar por el agua era la puerta para posteriormente pagar por otros elementos de la naturaleza, como los peces o el bosque. A pesar de todo ello, la responsabilidad, por ley, era ineludible. Los colonos, además, necesitaban estar al día en sus pagos para poder acceder a proyectos financiados por el Estado. 
Los awajún aceptaron de mala gana la creación de la tarifa. Pasaron de largo todo el proceso de hacer balances hídricos para estimar un pago justo. Concluyeron arbitrariamente que en sus predios se usaban 14000 metros cúbicos de agua por hectárea. A partir de ello, decidieron cobrar S/. 40 por el riego de una hectárea. La hectárea fue convertida en «camión» o «camión y medio», dependiendo del tamaño del vehículo que transportara la cosecha y el estado de ánimo del tranquero, el funcionario responsable de cobrar a todo medio de transporte que saliera de la comunidad cargando arroz. Dado que los awajún seguían alquilando sus tierras debido a que fracasó su iniciativa como desarrolladores agrícolas, decidieron obligar a sus arrendatarios el pago del derecho de uso de agua, como una de las condiciones para seguir con los contratos de alquiler.

De ese modo, la creación de la comisión de regantes desbordó los objetivos explícitos por los cuales buscó crearse. Más allá del uso eficiente del agua, de la transparencia y de la igualdad en la participación (todos principios de la GIRH), la comisión se planteó como la arena para negociar - y posteriormente controlarla intrusión de población colona en el territorio indígena. En el proceso, la acción colectiva para controlar los comunes se remite a las acciones más significativas del grupo predominante en la comunidad: las familias awajún. La participación de los wampis queda al margen, aunque será importante en el futuro, como veremos en la siguiente sección.

\section{LA COMISIÓN, DESPUÉS}

Luego de ser creada, la comisión instaló una pequeña oficina al ingreso del anexo de San Francisco. Al principio, para garantizar su mantenimiento, se solicitó a los miembros una cuota de pago semestral para solventar los gastos de pasajes del presidente de la comisión o alguno de sus miembros. Los primeros presidentes fueron awajún y en ese tiempo emplearon la comisión para mediar asuntos que escapaban a controversias hídricas, como problemas familiares, asuntos domésticos, deudas, e incluso brujería. De ese modo, la pertenencia a una familia antigua y el liderazgo individual fueron invistiendo de legitimidad a la Comisión. Esta, además, logró regular los arrendamientos de tierra a partir del control de los canales. Ello condujo a un período importante de generación de ingresos por rentas y ahorro.

Hacia 2010, la Comisión de Regantes de Bajo Naranjillo afianzó su rol como mediador en controversias hídricas y garante de la preservación las lógicas de convivencia awajún sobre el manejo del agua. Los awajún fueron depositando 
cada vez más confianza en ella, y eventualmente relegaron otras acciones que antes solían coordinar entre familias, como el ipaаmamu. De hecho, en este período se incorpora esta práctica para limpiar los canales de riego en la que se incorporó tanto a awajún y wampis como a colonos. Que todos ellos hayan quedado en buenos términos marcó a la Comisión de Regantes como una organización representativa de los intereses awajún y se llenó el vacío que dejó la OAAM cuando se mudó a Moyobamba como FERIAAM. Incluso los awajún de otras comunidades comenzaron a referirse a la comisión como a un organismo representativo indígena en temas de agua (y luego en otros temas, en general). Actuaban de facto, como un órgano consultivo en los procesos de creación de otras comisiones de regantes o en la difusión de la GIRH.

Hacia 2013 comenzaron a aparecer resultados inesperados. Los arrendatarios de los awajún que pagan la tarifa por ellos brindan sus datos en los comprobantes de pago. En los recibos figuran sus razones sociales, y de hecho es una práctica que les conviene, dado que emplean estos comprobantes como sustento para justificar futuros préstamos agrícolas. Para la JUCAM (Junta de Usuarios de la Cuenca del Alto Mayo) y la Autoridad Local del Agua, los pagadores son los sujetos que tienen el derecho por el uso del agua, a pesar de que esta atraviesa territorio indígena titulado. Debido a ello, algunos arrendatarios han comenzado a impedir que los awajún usen el agua canalizada que pasa por sus predios para el riego de sus parcelas.

En paralelo, un importante grupo de wampis se mantuvo al margen de la comisión, debido a que su principal cultivo no es el arroz, sino el café y el cacao. Al trabajar directamente la tierra y ser responsables de la comercialización del producto, las alzas de precio los han beneficiado y han podido invertir en el mejoramiento de sus condiciones de vida, accediendo a mejores servicios de salud, asesoría económica y conectividad, entre otros. Sin embargo, al estar en la periferia del debate indígena, carecen de la experiencia y del liderazgo necesario para respaldar a los awajún en la recuperación de sus derechos por el agua. Y, en última instancia, es una agenda con la que no se encuentran del todo comprometidos.

\section{BRICOLAJE: LÍMITES Y POSIBILIDADES}

El proceso de bricolaje involucra recurrir a arreglos institucionales previos, como prácticas y significados socialmente aceptados, para adaptar nuevas burocracias y lógicas de gobierno. Este proceso se desarrolla en varios momentos de la historia 
de Bajo Naranjillo, cuyo esfuerzo por acostumbrarse al lexicón del Estado deja algunos legados inesperados en el uso, control y acceso a agua y tierras.

En los inicios de Bajo Naranjillo, las ideas de familia y reunión se readaptan para incorporar nuevas nociones y prácticas, como la pertenencia a una comunidad y el trabajo en una cooperativa. La economía política del territorio, sin embargo, planteó restricciones a las posibilidades de ampliar la resignificación de estos términos. La idea de una «gran familia» encuentra sus límites cuando se plantea el monocultivo de arroz como respuesta ante la invasión del territorio.

Por otro lado, el ipaamamu probó ser una dinámica efectiva bajo ciertas circunstancias y se incorporó en nuevas acciones de organización colectiva, sustentando las labores cooperativas. En este período las lógicas awajún y wampis se emplean para dar sentido - incluso podría decirse «llenar de contenido»—a categorías externas que terminan replanteando profundamente las dinámicas de interacción entre indígenas y el control sobre agua y suelos.

En un segundo período, entrando al año 2000, encontramos otra dinámica adaptativa. Aquí la comisión de regantes es tratada como una arcilla con la que se pueden moldear distintas formas que sirvan intereses plurales que definitivamente desbordan aquellos que tuvo cuando fue ideada en el papel. Para que este nuevo organismo funcione, es investido con la legitimidad de arreglos previos, específicamente, de aquellos vinculados con la jerarquía awajún. De esta manera, el control territorial ejercido por las principales familias awajún encuentra nuevos espacios con los organismos de gobierno hídrico emergentes y pueden, en ellos, reproducir su dominio sobre cómo se deben conducir procesos deliberativos y cómo asignar el acceso a agua y tierras. Pero el proceso, una vez más, presenta restricciones, esta vez bajo la lógica del mercado que sostiene el establecimiento de un tipo de valor que garantiza un tipo de derecho.

En ambos momentos de la historia de la comunidad se encuentran dinámicas de alteración: esfuerzos por convertir en inteligible lo extraño y en traducir construcciones burocráticas externas a las lógicas y categorías propias -incluso aquellas que no eran originalmente awajún-, como parece ocurrir con la dimensión colectiva del ipaатати. La alteración es necesaria, pues constituye la interfaz entre maneras diferentes - $\mathrm{y}$ hasta contrapuestas - de comprender modos de organizarse y gobernar. Y algunas cosas cambian en el proceso, como la incorporación de nuevas prácticas para el manejo colectivo de agua y tierras, o la generación de expertise en la negociación con diferentes actores.

Sin embargo, en este caso la alteración no conduce a la creación de instituciones cualitativamente diferentes sino al anidamiento de lo que ya existía para garantizar 
su continuidad. Las prácticas y los resultados de los proyectos agrícolas e hídricos dejan legados difícilmente mitigables, generando un conjunto de respuestas que apuestan por aproximaciones más cautas ante los avances del desarrollo. De este modo, la plausibilidad de instalar nuevas instituciones para el gobierno hídrico depende no solo de los arreglos locales para el control de agua y tierras, arreglos que ponen entre paréntesis la idea de «comunidad» como el sinónimo de la acción colectiva, sino también de la inflexibilidad del Estado en la traducción de nuevas burocracias y en los legados de experiencias previas de desarrollo. Una aplicación acrítica de nuevas categorías de gestión puede terminar conduciendo, como deja en evidencia este caso, a nuevas dinámicas de alienación de derechos.

\section{REFERENCIAS BIBLIOGRÁFICAS}

Abers, R. N. (2007). Organizing for governance: Building collaboration in Brazilian river basins. World Development, 35, 1450-1463. https://doi.org/10.1016/j. worlddev.2007.04.008

Bant, Astrid (1994). Parentesco, matrimonio e intereses de género en una sociedad amazónica: el caso aguaruna. Amazonía Peruana, XII(14), 77-103.

Benouniche, Maya, Margreet Zwarteveen y Marcel Kuper (2014). Bricolage as innovation: Opening the Black Box of Drip Irrigation System. Irrigation and Drainage, 63(5), 651-658. https://doi.org/10.1002/ird.1854

Bergman, Roland (1990). Economía amazónica: estrategias de subsistencia en las riberas del Ucayali en el Perú. Lima: CAAAP.

Borios, Stephanie (2005). Los asháninka y la pesca. Ikanta Ishimajeita Ashaninka. Lima: IBC.

Braga, B., P. Varella y H. Gonzalves (2011). Transboundary water management of the Amazon basin. Water Resources Development, Special Issue: Managing Transboundary Waters of Latin America, 27(3), 477-496 https://doi.org/10.1080/0790 0627.2011 .595382

Brown, Michael F. (2014). Upriver: the turbulent life and times of an Amazonian people. Cambridge: Harvard University Press. https://doi.org/10.4159/harvard.9780674735583

Brown, Michael F. (1984). Una paz incierta. Historia y cultura de las comunidades aguarunas frente al impacto de la carretera marginal. Lima: CAAAP.

Calderón, Luis (2013). Hacia una radiografía de los pueblos awajún y wampis del Alto Marañón, Amazonas. Lima: GIZ.

Cleaver, Frances (2012). Development through bricolage. Rethinking institutions for natural resource management. Londres: Earthscan/Routledge. 
Cleaver, Frances y Jessica De Koning (2015). Furthering critical institutionalism. International Journal of the Commons, 9(1), 1-18. https://doi.org/10.18352/ijc.605

Cleaver, Frances y A. Toner (2006). The evolution of community water governance in Uchira, Tanzania: the implications for equality of access, sustainability and effectiveness. Natural Resources Forum, 30(3), 207-2018. https://doi. org/10.1111/j.1477-8947.2006.00115.x

Collier, D. (2011). Understanding process tracing. Political science and politics, 44(4), 823-830. https://doi.org/10.1017/S1049096511001429

Conservación Internacional (2014). Governance + restoration of riverine vegetation + aquatic resources in the native community of Shampuyacu. Brochure informativo de Proyecto. Recuperado de: http://www.conservation.org/global/peru/publicaciones/Documents/FACTSHEET\%20SWIFT\%20ENLGISH\%20final.pdf

De Souza, M., F. Torrente Veloso, L. Britto dos Santos y R. Bernardo da Silva (2014). Governanza de recursos comuns: bacias hidrograficas transfronteirizas. Revista Brasilerira de Politica Internacional, 57(2), 152-175. https://doi. org/10.1590/0034-7329201400309

De Koning, Jessica (2011). Reshaping institutions: Bricolage processes in smallholder forestry in the Amazon. Tesis de doctorado. Universidad de Wageningen.

De Koning, Jessica y Charlotte Benneker (2013). Bricolage Practices in Local Forestry. En Bas Arts, Jelle Behagel, Séverine van Bommel, Jessica de Koning y Esther Turnhout (eds.), Forest and Nature Governance - A Practice Based Approach. Dordrecht: Springer, 49-67.

Gamboa, Aída (2014). Las demandas indígenas en el conflicto social hidrocarburífero entre el pueblo indígena amazónico quechua del Pastaza y la empresa Pluspetrol Norte entre los años 2012 y 2013. Tesis de Maestría en Ciencia Política y Gobierno. PUCP.

Garay, Johanna (2004). Derechos indígenas de acceso a los recursos hidrobiológicos. El caso de las comunidades indígenas del Purús en la Amazonía Peruana. Tesis de maestría en Derecho Ambiental. Universidad Internacional de Andalucía.

Greene, Shane (2009). Caminos y carretera. Acostumbrando la indigeneidad en la selva peruana. Lima: IEP.

Guallart, José María (1990). Entre pongo y cordillera: historia de la etnia aguarunahuambisa. Lima: CAAAP.

Larson, Mildred (1977). Organización sociopolítica de los aguaruna (jíbaro): sistema de linajes segmentarios. Revista del Museo Nacional, XLIII, 467-489.

Mehta, Lyta, Melissa Leach, Peter Newell, Ian Scoones, Kaly Sivaramakrishnan, Kalyanakrishnan y Sally-Anne Way (2002). Explorando conocimientos sobre instituciones e incertidumbre: nuevas direcciones en el manejo de recursos naturales. En Richard Chase Smith y Danny Pinedo (eds.), El cuidado de los bienes 
comunes. Gobierno y manejo de los lagos y bosques en la Amazonía (pp. 100154). Lima: IEP, IBC.

MINAM (2009). Evaluación local integrada y estrategia de adaptación al cambio climático en el Río Mayo. Moyobamba: MINAM, GEF, PNUD.

Ocampo, Ada (1994). Sistematización de la experiencia en seguimiento y evaluación del proyecto especial Alto Mayo en Perú. O. Feinstein (ed.), Experiencias latinoamericanas en seguimiento y evaluación (pp. 151-205). Quito: IICA y FIDA.

Ostrom, Elinor (2005). Understanding Institutional Diversity. Princeton: Princeton University Press.

Ostrom, Elinor (1990). Governing the Commons: The Evolution of Institutions for Collective Action. Cambridge, MA: Cambridge University Press. https://doi. org/10.1017/CBO9780511807763

Pinedo, Danny, Percy Summers, Richard Chase Smith y Angélica Almeyda (2002). Manejo comunitario de recursos naturales como un proceso no lineal: un estudio de caso en la llanura de inundación de la Amazonía peruana. En Richard Chase Smith y Danny (eds.), El cuidado de los bienes comunes. Gobierno y manejo de los lagos y bosques de la Amazonía. Lima: IBC.

RAISG - Red Amazónica de Información Socioambiental Georreferenciada (2012). Amazonía 2012. Áreas Protegidas y Territorios Indígenas. Recuperado de: https://raisg.socioambiental.org/system/files/AMAZON2012_espanhol.pdf

Ráez, Ernesto (2010). «Viene más la pobreza»: conflictos socioambientales y megaproyectos de infraestructura vial y energética en la Amazonía peruana. En Patricia Ames y Víctor Caballero (eds.), SEPIA XVIII. Perú: el problema agrario en debate. Lima: SEPIA.

Regan, James e Isaac Paz (2008). Formas de organización y matrimonio dravídico entre los awajún: los doce matrimonios de diez hermanos. Revista de Antropología de la UNMSM, 12(6), 199-206.

Regan, J. (2003). Valoración cultural de los pueblos awajún y wampis. Lima: Conservación Internacional.

Rivas, Roxani (2004). El gran pescador: técnicas de pesca entre los cocama-cocamillas de la Amazonía peruana. Lima: Fondo Editorial de la PUCP.

Romio, Silvia (2014). Entre discurso político y fuerza espiritual. Fundación de las organizaciones indígenas awajún y wampis (1977-1979). Anthropologica, 32, 139-158.

Sarasara, César (1999). Pueblos desplazados, derechos humanos y vocación de paz. En A. Bonilla (ed.), Ecuador-Perú. Horizontes de la negociación y el conflicto (pp. 343-350). Quito: FLACSO Ecuador. 
Sehring, Jenniver (2009). The Politics of Water Institutional Reform in Neopatrimonial States. A Comparative Analysis of Kyrgyzstan and Tajikistan. La Haya: VS Verlag für Sozialwissenschaften.

Siegmund-Schultze, M., V. Rodorff, J. Koppel y M. Sobral (2015). Paternalism or participatory governance? Efforts and obstacles in implementing the Brazilian water policy in a large watershed. Land Use Policy, 48, 120-130. https://doi. org/10.1016/j.landusepol.2015.05.024

Soria, Carlos y Vanessa Rodríguez (2008). El marco legal y consuetudinario de la pesca de subsistencia en el río Pichis, Perú. En Danny Pinedo y Carlos Soria (eds.), El manejo de las pesquerías en los ríos tropicales de Sudamérica. Recuperado de: http://www.ibcperu.org/doc/isis/9428.pdf

Taylor, Anne Christine (1998). Jivaro kinship: simple and complex formulas. En Maurice Godelier, Thomas Trautmann y Franklin Tjon Sie Fat (eds.), Transformations in kinship (pp. 187-213). Washington: Smithsonian Institution Press.

Taylor, Anne Christine (1993). Remembering to Forget: Identity, Mourning and Memory Among the Jivaro. Man, 28(4), new series, 653-678. doi:10.2307/2803991

Tello, Rodolfo (2001). Las prácticas matrimoniales en la comunidad nativa aguaruna de Nazareth: formas, percepciones y cambios en el contexto de las relaciones interculturales a fines del siglo XX. Tesis de Licenciatura en Antropología. Universidad Nacional Mayor de San Marcos.

Uriarte, Luis (2007). Organización social, sabiduría y poder. En Santos Granero, F. y F. Barclay (eds.), Guía etnográfica de la Alta Amazonía. Volumen VI: Achuar / Candoshi. Lima: Institut français d'études andines. doi :10.4000/books.ifea.8188

Urteaga, Patricia (1993). El sistema jurídico y su relación con la cultural nativa. Tesis de Licenciatura en Derecho. Pontificia Universidad Católica del Perú.

Villacréz, Roberto (2012). Una lucha por la dignidad y la vida»: el conflicto entre la comunidad achuar y las empresas petroleras en la cuenca del rio Corrientes. Tesis de Licenciatura en Ciencia Política y Gobierno. PUCP.

Verzijl, Andrés y Carolina Domínguez (2015). The powers of water-user associations: on multiplicity, fluidity, and durability in the Peruvian Andes. International Journal of the Commons, 9(1), 107-128. DOI: http://doi.org/10.18352/ijc.537

Works, Marianne (1984). El proceso de desarrollo y la experiencia de cambio: situación de los aguarunas del Valle del Alto Mayo. Amazonía Peruana, 5(10), 119-128. 